\title{
High Pressure Mass Spectrometry: The Generation of Mass Spectra at Operating Pressures Exceeding 1 Torr in a Microscale Cylindrical Ion Trap
}

\author{
Kenion H. Blakeman ${ }^{1}$, Derek W. Wolfe ${ }^{1}$, Craig A. Cavanaugh ${ }^{2}$, and J. Michael \\ Ramsey*1,2,3,4 \\ ${ }^{1}$ Department of Chemistry, ${ }^{2}$ Department of Applied Physical Sciences, ${ }^{3}$ Department of \\ Biomedical Engineering, and ${ }^{4}$ Carolina Center for Genome Sciences, University of North \\ Carolina at Chapel Hill, Chapel Hill, North Carolina 27599, United States \\ AUTHOR EMAIL ADDRESS jmramsey@unc.edu
}

\section{Contents:}

Figure S-1. Applied Axial RF Voltage as a Function of Pressure p. S2 


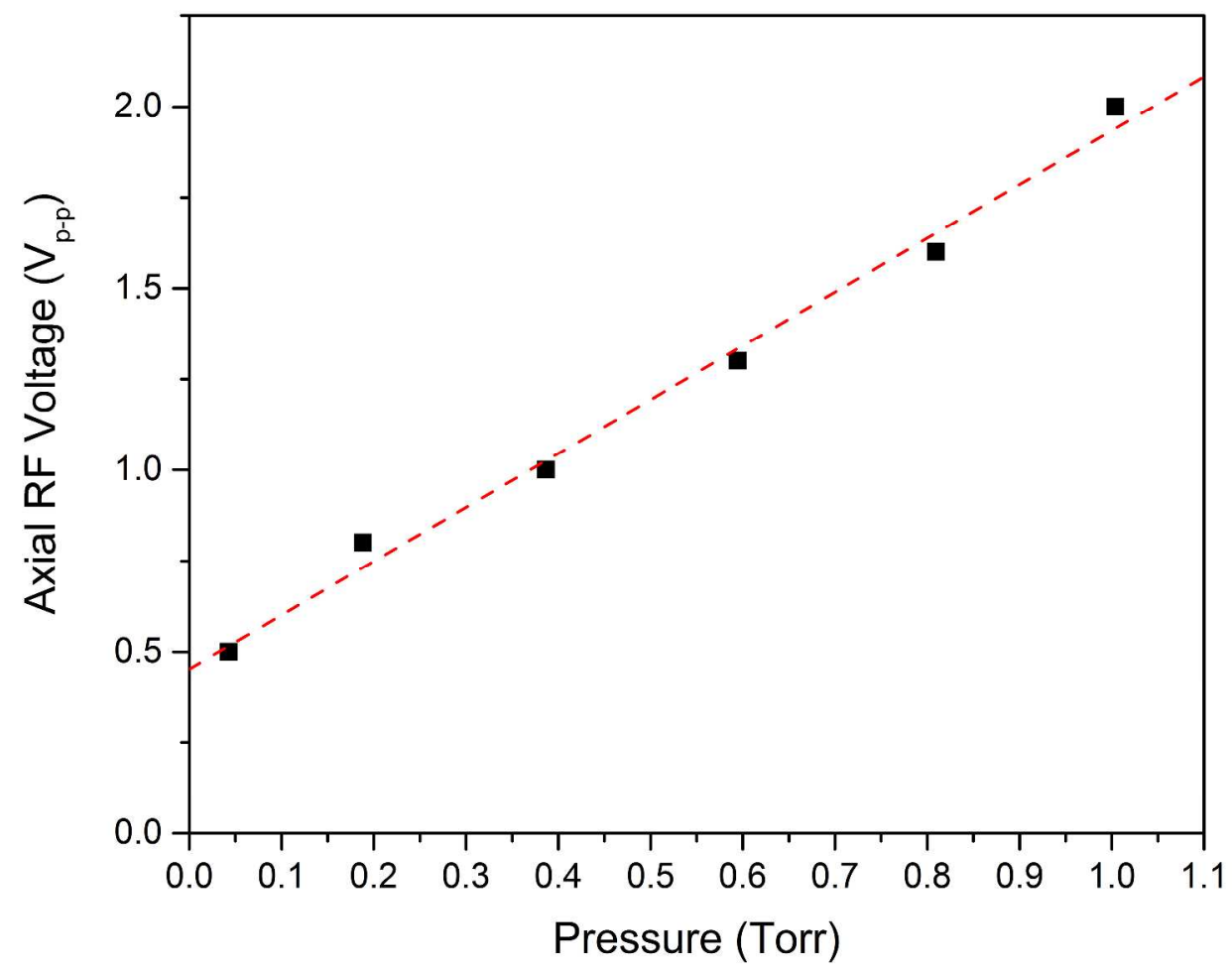

Figure S1. Axial RF voltage $\left(\mathrm{V}_{\mathrm{p}-\mathrm{p}}\right)$ was optimized for various pressures, with xenon used as the analyte.

As the pressure for mass analysis was increased, the magnitude of the axial RF voltage was increased to maintain optimal resolution at each pressure. The slope of the best-fit line is $1.48 \pm 0.07 \mathrm{mV}$-Torr ${ }^{-1}\left(\mathrm{R}^{2}=0.991\right)$. The minimum value for voltage was $0.5 \mathrm{~V}_{\mathrm{p}-\mathrm{p}}$ at the lowest pressure (0.043 Torr), and the maximum value was $2.0 \mathrm{~V}_{\mathrm{p}-\mathrm{p}}$ at the highest pressure (1 Torr). The axial RF frequency was approximately $1 / 3$ the frequency of the drive $\mathrm{RF}$, corresponding to the hexapolar resonance. 